\title{
Rapid Alteration in Circulating Free Thyroxine Modulates Pituitary Type II 5' Deiodinase and Basal Thyrotropin Secretion in the Rat
}

\author{
Susan L. Abend, Shih Lieh Fang, Sharon Alex, Lewis E. Braverman, and Jack L. Leonard \\ Departments of Medicine, Nuclear Medicine and Physiology, University of Massachusetts Medical School, \\ Worcester, Massachusetts 01655
}

\begin{abstract}
TSH secretion is decreased by both $T_{4}$ and $T_{3}$. This negative feedback control of TSH secretion has been correlated with an increase in pituitary nuclear $T_{3}$ content, and it is not clear whether $T_{4}$ exerts its effect directly on the thyrotroph or after its deiodination to $T_{3}$. However, levels of the pituitary enzyme catalyzing $T_{4}$ to $T_{3}$ conversion, 5 D-II, are decreased in the presence of an increased amount of $T_{4}$. Thus, it is unclear why the thyrotroph would have a mechanism for modulating the production of $T_{3}$, if $T_{3}$ is, in fact, the sole bioactive signal providing negative feedback inhibition.

To examine this apparent paradox, we administered EMD 21388 , a compound which inhibits the binding of $T_{4}$ to transthyretin resulting in a rapid increase in circulating free $T_{4}$ levels, to rats pretreated with radiolabeled $T_{4}$ and $T_{3}$. We observed increases in pituitary and liver $T_{4}$ content of $>150 \%$, without increases in the respective tissue $T_{3}$ contents. The EMD 21388-treated rats also exhibited a $25 \%$ decrease in pituitary 5'D-II activity $\left(103.8 \pm 15.8 \mathrm{fmol}{ }^{125} \mathrm{I}\right.$ released $\cdot \mathrm{mg}$ pro$\operatorname{tein}^{-1} \cdot h^{-1}$, vs. control, $137.4 \pm 15.9$, mean $\left.\pm S E\right)$, as did rats treated with sodium salicylate, another compound that inhibits $T_{4}$-TTR binding (100.8 \pm 7.1$)$. TSH levels significantly decreased $2 \mathrm{~h}$ after the administration of EMD 21388. These data demonstrate that despite a $T_{4}$-mediated decrease in pituitary 5'D-II activity, an increase in $\mathrm{T}_{4}$ independently decreases TSH secretion. (J. Clin. Invest. 1991. 88:898-903.) Key words: thyrotropin • flavonoid • deiodinase • transthyretin • thyroxine
\end{abstract}

\section{Introduction}

Thyrotropin (TSH) ${ }^{1}$ regulates the synthesis and secretion of thyroxine $\left(\mathrm{T}_{4}\right)$ and triiodothyronine $\left(\mathrm{T}_{3}\right)$ from the thyroid gland. Pituitary TSH secretion is stimulated by thyrotropin releasing hormone (TRH), and decreased by other hypothalamic factors, including dopamine and somatostatin (1). Thyroid hormones play a major role in regulating TSH secretion.

Portions of this work were presented to the 72nd Annual Meeting of the Endocrine Society, 20-24 June 1990, and the 10th International Thyroid Congress, 3-8 February 1991.

Received for publication 21 November 1990 and in revised form 30 April 1991.

1. Abbreviations used in this paper: 5'D-II, type II $5^{\prime}$ deiodinase; $\mathrm{T}_{3}$, triiodothyronine; $\mathrm{T}_{4}$, thyroxine; $\mathrm{TRH}$, thyrotropin-releasing hormone; TSH, thyrotropin; TTR, transthyretin.

J. Clin. Invest.

(c) The American Society for Clinical Investigation, Inc.

$0021-9738 / 91 / 09 / 0898 / 06 \$ 2.00$

Volume 88, September 1991, 898-903
In thyroidectomized rats, the administration of physiologic replacement doses of $\mathrm{L}_{-} \mathrm{T}_{3}$ decreases serum TSH by $\sim 50 \%$ in 2 $h$, and a similar decrease is seen after the administration of $\mathrm{L}_{-} \mathrm{T}_{4}(2,3)$. Silva and Larsen reported that, following the intravenous administration of $70 \mathrm{ng} \mathrm{L-T} / 100 \mathrm{~g}$ body weight or a 10-fold higher amount of $T_{4}$, the fall in serum TSH was associated with a rise in the percentage of $T_{3}$ bound to pituitary nuclear receptors (3). This led to the suggestion that $T_{4}$ exerts its inhibitory effect on TSH secretion primarily after its deiodination to $T_{3}$.

This idea was further supported by a number of subsequent findings. First, pituitary TSH suppression was dependent upon nuclear $T_{3}$ content and serum $T_{3}$ concentration (4). Second, the simultaneous administration of replacement doses of $L_{-} T_{3}$ and $L-T_{4}$ doubled the pituitary nuclear $T_{3}$ content and augmented the decrease in serum TSH beyond that of $L-T_{3}$ administration alone (4). Furthermore, the administration of iopanoic acid, a potent inhibitor of $T_{4}$ to $T_{3}$ conversion, prevented the $T_{4}$ induced decrease in TSH secretion in thyroidectomized rats $(5,6)$. Iopanoic acid was also found to block the effect of $T_{4}$ on TRH-induced TSH secretion in euthyroid rats (7). In intact rats, Emerson et al. reported that serum $T_{3}$ appears to more closely correlate with serum TSH levels than serum $T_{4}$ (8). It became clear, then, that both circulating $T_{3}$ and the intrapituitary conversion of $T_{4}$ to $T_{3}$ play key roles in the regulation of TSH secretion. The physiological importance of pituitary iodothyronine 5 -deiodination was underscored by the finding that $50 \%$ of pituitary $T_{3}$ is generated locally from $T_{4}$ in euthyroid rats (9).

If $T_{3}$ is the major signal inhibiting TSH secretion, then under conditions in which serum $T_{4}$ is increased and serum $T_{3}$ remains unchanged, any decrease in TSH levels should be dependent upon local pituitary $T_{3}$ production via type II $5^{\prime}$ deiodinase (5'D-II), the pituitary enzyme catalyzing $T_{4}$ to $T_{3}$ conversion (10). Interestingly, however, numerous studies have provided in vivo and in vitro evidence that an increase in the $T_{4}$ concentration rapidly decreases 5 D-II activity (11-16). This would appear paradoxical in a system thought to respond in a negative-feedback fashion, since the intracellular concentration of $T_{3}$, the bioactive signal, would be expected to remain constant over a wide range of $T_{4}$ concentrations.

To examine this paradox, we pretreated rats with $\left[{ }^{125} \mathrm{I}\right]-\mathrm{T}_{4}$ and $\left.{ }^{131} \mathrm{I}\right]-\mathrm{T}_{3}$ and studied the intrapituitary thyroid hormone content and 5'D-II activity after administration of EMD 21388 (3-methyl-4',6-dihydroxy-3',5'-dibromo-flavone). This synthetic flavonoid blocks the binding of $T_{4}$ to transthyretin (TTR), the major thyroid hormone binding protein in the rat. Intraperitoneal administration of EMD 21388 increases the serum free $T_{4}$ concentration and decreases the serum total $T_{4}$ within $3 \mathrm{~min}$, without affecting serum free $T_{3}$ levels (17). Basal serum TSH levels decrease within 1-2 $h$ after EMD 21388 administration, and remain depressed for at least $4 \mathrm{~h}(17,18)$. 
This model allowed us to examine the negative-feedback control of basal TSH secretion under steady-state conditions, without requiring the administration of pharmacologic amounts of thyroid hormones.

We observed a $>150 \%$ increase in the pituitary $T_{4}$ content in the EMD 21388-treated animals, without an increase in pituitary $T_{3}$ content derived from either local deiodination or from the circulation. Pituitary 5'D-II activity was decreased. These findings were associated with a decrease in serum TSH concentration. Thus it appears likely that $T_{4}$ can act independently to suppress basal TSH secretion in euthyroid rats, and may, therefore, be an additional bioactive signal to the thyrotroph.

\section{Methods}

Animals and reagents. Male Sprague-Dawley rats, $200-250 \mathrm{~g}$, were obtained from Charles River Laboratories (Kingston, RI). They were maintained under standard conditions with a 12-h light cycle, and were allowed ad libitum access to Purina Standard Chow (Ralston-Purina, St. Louis, MO) and water before all studies.

EMD 21388 was kindly supplied by E. Merck (Darmstat, FRG) and was dissolved in $40 \mathrm{mM} \mathrm{NaOH}$ and given intraperitoneally. Sodium salicylate was dissolved in $\mathrm{H}_{2} \mathrm{O}$ and given by gavage. $\left[{ }^{125} \mathrm{I}\right]-\mathrm{T}_{4}$ and $\left[{ }^{131} \mathrm{I}\right]-$ $T_{3}$ were freshly prepared from $T_{3}$ and $T_{2}$ (Henning, Berlin, FRG) by methods previously described (19). ${ }^{125}$ I was obtained from Amersham (Arlington Heights, IL), and ${ }^{131}$ I from New England Nuclear (Boston, MA). The purity of each radiolabeled iodothyronine was $>95 \%$, as determined by HPLC analysis. Both tracers were mixed in normal rat serum and administered intravenously, or used in the determination of 5'D-II activity.

Experimental procedures. Tissue iodothyronine levels were examined in rats given $250 \mu \mathrm{Ci}$ of $\left[{ }^{125} \mathrm{I}\right]-\mathrm{T}_{4}(2.2 \mathrm{Ci} / \mu \mathrm{mol}) 16 \mathrm{~h}$, and $25 \mu \mathrm{Ci}$ $\left.{ }^{[131} \mathrm{I}\right]-\mathrm{T}_{3}(\sim 2.5 \mathrm{Ci} / \mu \mathrm{mol}) 1 \mathrm{~h}$ before the study, using a modification of the method of Silva et al. (9). At time 0, group I rats were given i.p. ketamine anaesthesia and sacrificed by aortic exsanguination. Group Il rats were given $40 \mathrm{mM} \mathrm{NaOH}$ vehicle, and group III rats were given EMD $21388(2 \mu \mathrm{mol} / 100 \mathrm{~g}$ i.p.). These two groups were sacrificed $1 \mathrm{~h}$ later. Rats were perfused with $60-90 \mathrm{ml}$ of saline. Pituitaries and $0.5 \mathrm{~g}$ liver were harvested and homogenized in buffer containing $10 \mathrm{mM}$ Hepes and $10 \mathrm{mM}$ iopanoic acid. Radioactivities in aliquots of serum, liver, and pituitary homogenates were measured in a gamma well counter (Autogamma 5000; Packard Instrument Co., Inc., Arlington Heights, IL). Corrections for decay, energy cross-over, and background were made for both isotopes. Tissue $T_{4}$ and $T_{3}$ content were analyzed using descending paper chromatography in a solvent system containing 1:5:6 hexane, $t$-amyl alcohol, and $2 \mathrm{~N} \mathrm{NH}_{4} \mathrm{OH}(20)$. Bands of $\mathrm{T}_{4}$ and $\mathrm{T}_{3}$ were identified by staining with deazotized sulfanilic acid (Pauly's reagent) and iodine was identified with palladium chloride stain. Each $T_{3}$ and $T_{4}$ band was cut, counted, and the percentage of total counts was determined by dividing the counts for each isotope in both the $T_{3}$ and $T_{4}$ bands by the total counts present on each paper strip. The percentage of total counts was then multiplied by the counts present in a milligram of tissue, and expressed as a percent of the total counts of each isotope administered.

In the second set of experiments, group I rats were treated with $\mathbf{4 0}$ $\mathrm{mM} \mathrm{NaOH}$ vehicle i.p. Group II rats received EMD $21388(2 \mu \mathrm{mol} /$ $100 \mathrm{~g}$ i.p.), and group III animals received sodium salicylate $(30 \mathrm{mg} /$ $100 \mathrm{~g}$ p.o.). All rats were sacrificed $1 \mathrm{~h}$ later by decapitation and trunk blood and pituitaries were collected. Serum was assayed for TSH, total $T_{4}$, total $T_{3}$, and free $T_{4}$. Pituitaries were immediately placed in liquid nitrogen, and later homogenized in $800 \mu \mathrm{l}$ of a buffer containing 250 $\mathrm{mM}$ sucrose, $20 \mathrm{mM}$ Hepes, $1 \mathrm{mM}$ EDTA, and $1 \mathrm{mM}$ DTT, pH 7.0, just before measuring $5^{\prime} \mathrm{D}-\mathrm{II}$ activity.

In the third experiment, rats were treated with either $40 \mathrm{mM} \mathrm{NaOH}$ vehicle or EMD $21388(2 \mu \mathrm{mol} / 100 \mathrm{~g}$ i.p. $)$ and sacrificed 1 or $2 \mathrm{~h}$ later. Trunk blood was collected, and serum was assayed for TSH.
Assays. Serum $\mathrm{T}_{4}$ and $\mathrm{T}_{3}$ were measured by RIA as previously described (21). Serum TSH concentrations were measured by RIA using materials kindly supplied by the National Institutes of Diabetes, Digestive and Kidney Diseases National Hormone and Pituitary Program, National Institutes of Health, Bethesda, MD. All three hormones were measured in duplicate, in random order, and in the same assay for each experiment. The intraassay coefficients of variation were: $\mathrm{T} 4,<1 \%$; T3, < $5 \%$; and TSH, $<1 \%$.

Salicylate levels were determined by a modification of Trinder's method (22) in the serum of salicylate-treated rats, and in equilibrium dialysis buffer after an 18 -h incubation with serum containing $2.1 \mathrm{mM}$ sodium salicylate. Percent free $T_{4}$ was measured in duplicate by equilibrium dialysis of undiluted serum at $37^{\circ} \mathrm{C}$ for $18 \mathrm{~h}$ as described previously (21), and the free $\mathrm{T}_{4}$ concentration was calculated as the product of total $T_{4}$ and percent free $T_{4}$.

To assess whether a significant concentration of "free" EMD 21388 could be present in vivo and available to cells, we used the ability of EMD 21388 to displace $T_{4}$ from serum as an index of "free" flavonoid. In the first experiment, increasing quantities of EMD 21388 were added to serum aliquots, creating concentrations of 0-5 mM. In the second experiment, rats were treated with either $2 \mu \mathrm{mol} / 100 \mathrm{~g}$ or 4 $\mu \mathrm{mol} / 100 \mathrm{~g}$ EMD 21388 intravenously, sacrificed in $3 \mathrm{~min}$, and trunk blood was obtained. Each serum sample was dialyzed against an equal volume of phosphate buffer for $18 \mathrm{~h}$ at $37^{\circ}$. After dialysis, the dialysate was added to an equal volume of fresh normal rat serum, and this mixture was incubated with tracer $\left[{ }^{125} \mathrm{I}\right]-\mathrm{T}_{4}$ for $30 \mathrm{~min}$. $50 \mu \mathrm{l}$ aliquots of each incubation mixture were loaded onto nondenaturing PAGE gels and run for $5 \mathrm{~h}$ at $140 \mathrm{~V}$ in recirculating $0.02 \mathrm{M}$ phosphate buffer (23). PAGE-gels were dried and exposed for radioautography for $24 \mathrm{~h}$, and the quantity of radiolabeled T4 bound to TTR was determined by counting the labeled TTR spot and expressing it as a percentage of the total counts in that aliquot.

${ }^{5} \mathrm{D}-\mathrm{II}$ activity was measured by the release of ${ }^{125} \mathrm{I}$ from $\left[{ }^{125} \mathrm{I}\right]-\mathrm{T}_{4}$ in the presence of $1 \mathrm{mM}$ propylthiouracil, as previously described (12), using $20-\mu 1$ aliquots of pituitary homogenate and 100 or $200 \mathrm{pM}\left[{ }^{125} \mathrm{I}\right]-$ $\mathrm{T}_{4}$ as substrate. Protein determinations were performed using the BioRad Protein Assay (Bio-Rad Laboratories, Inc., Richmond, CA).

Statistical analysis. All data are presented as the mean \pm SE. Data were analyzed using one way analysis of variance (ANOVA) and Student-Neumann-Keuls multiple comparisons test (SNK), or analysis of covariance, where appropriate.

\section{Results}

Effect of EMD 21388 on the kinetics of radioiodine-labeled $T_{3}$ and $T_{4}$. The ratio of pituitary to serum ${ }^{125} \mathrm{I}$ counts in the control group at time zero $(0.23 \pm 0.02)$ was not different from that in the $\mathrm{NaOH}$-treated group at $60 \mathrm{~min}(0.20 \pm 0.02)$, indicating that the rats were in equilibrium at the time of the experiment. The ${ }^{125}$ I pituitary to serum ratio in the EMD 21388-treated group, however, was approximately double that of either control group $(0.47 \pm 0.06, P<0.05)$. Table I illustrates the pituitary content of $\left[{ }^{125} \mathrm{I}\right]-\mathrm{T}_{4},\left[{ }^{125} \mathrm{I}\right]-\mathrm{T}_{3}$, and $\left[{ }^{131} \mathrm{I}\right]-\mathrm{T}_{3}$. These results indicate that the differences in pituitary ${ }^{125} \mathrm{I}$ counts can be directly attributed to an increase in the pituitary $T_{4}$ content alone, and that this increase is not accompanied by a corresponding change in $\left[{ }^{125} \mathrm{I}\right]-\mathrm{T}_{3}$ levels. There was also no increase in the systemic contribution to pituitary $T_{3}$ content, as demonstrated by the pituitary $\left[{ }^{131} \mathrm{I}\right]-\mathrm{T}_{3}$ levels (Table I).

The content of hepatic radioiodine-labeled iodothyronines displayed a similar pattern (Table I). Again, the liver to serum ratio of ${ }^{125}$ I was markedly higher in the EMD 21388 treatment group than in either of the control groups. $(1.59+0.11$ in the EMD 21388-treated rats, vs. $0.50+0.04$ in the group I control rats, and $0.58+0.03$ in the group II control rats; $P<0.05$ by ANOVA). The liver content of $\left[{ }^{125} \mathrm{I}\right]-\mathrm{T}_{4}$ was elevated in the 
Table I. Pituitary and Liver Fractionated Radioiodothyronine Content in EMD 21388-treated Rats and Controls

\begin{tabular}{|c|c|c|c|c|c|c|}
\hline & \multicolumn{3}{|c|}{ Pituitary } & \multicolumn{3}{|c|}{ Liver } \\
\hline & $\begin{array}{cc}\text { Group } & \begin{array}{c}\text { I } \\
\text { Control } \\
(0 \mathrm{~h})\end{array}\end{array}$ & $\begin{array}{l}\text { II } \\
\text { Control } \\
(1 \mathrm{~h})\end{array}$ & $\begin{array}{c}\text { III } \\
\text { EMD }\end{array}$ & $\begin{array}{c}\text { I } \\
\text { Control } \\
(0 \mathrm{~h})\end{array}$ & $\begin{array}{c}\text { II } \\
\text { Control } \\
(1 \mathrm{~h})\end{array}$ & $\begin{array}{c}\text { III } \\
\text { EMD }\end{array}$ \\
\hline \multicolumn{7}{|l|}{$\begin{array}{c}\text { \% dose/mg } \\
\text { tissue }\end{array}$} \\
\hline$\left[{ }^{125} \mathrm{I}\right]-\mathrm{T}_{4} \times 10^{-7}$ & $3.27 \pm 0.46$ & $3.64 \pm 0.49$ & $5.70 \pm 0.52^{*}$ & $10.79 \pm 0.98$ & $9.11 \pm 1.20$ & $14.36 \pm 1.33^{*}$ \\
\hline$\left[{ }^{125} \mathrm{I}\right]-\mathrm{T}_{3} \times 10^{-7}$ & $2.25 \pm 0.33$ & $2.51 \pm 0.16$ & $2.97 \pm 0.49$ & $1.65 \pm 0.21$ & $1.98 \pm 0.10$ & $1.78 \pm 0.20$ \\
\hline$\left[{ }^{131} \mathrm{I}\right]-\mathrm{T}_{3} \times 10^{-5}$ & $1.80 \pm 0.24$ & $1.74 \pm 0.13$ & $1.63 \pm 0.14$ & $0.76 \pm 0.05$ & $0.95 \pm 0.12$ & $0.60 \pm 0.04$ \\
\hline
\end{tabular}

Rats were treated with $250 \mu \mathrm{Ci}$ of [ $\left.{ }^{125} \mathrm{I}\right]-\mathrm{T}_{4} 16 \mathrm{~h}$ before the study, and $25 \mu \mathrm{Ci}\left[{ }^{131} \mathrm{I}\right]-\mathrm{T}_{3} 1 \mathrm{~h}$ before the study. One control group was sacrificed at time 0 , and one control group was given $40 \mathrm{mM} \mathrm{NaOH}$ vehicle and sacrificed at $1 \mathrm{~h}$. EMD 21388-treated rats received $2 \mu \mathrm{mol} / 100 \mathrm{~g}$ and were sacrificed at $1 \mathrm{~h}$. The data include the results of two separate experiments, each with three to five rats per group, and are expressed as the mean \pm SE. ${ }^{*} P<0.05$ by ANOVA.

flavonoid-treated rats compared to rats in groups I and II, whereas the level of $\left[{ }^{125} \mathrm{I}\right]-\mathrm{T}_{3}$ was not different. The liver content of $\left.{ }^{131} \mathrm{I}\right]-\mathrm{T}_{3}$ (circulating $\mathrm{T}_{3}$ ) was slightly lower in the EMD 21388-treated rats.

Effect of EMD 21388 and salicylate administration on pituitary $5^{\prime} D$-II activity. To determine why an increase in the pituitary content of $T_{4}$ was not associated with a corresponding increase in pituitary $T_{3}$ content, we studied the $5^{\prime} \mathrm{D}$-II activity in pituitary homogenates of animals treated with either vehicle, EMD 21388, or sodium salicylate, another compound previously shown to partially inhibit $\mathrm{T}_{4}$ binding to TTR in the rat (24).

To ensure an optimal estimation of pituitary 5'D-II activity, we measured the rate of 5'D-II activity under reaction conditions that showed linear production of $T_{3}$ at $T_{4}$ concentrations approximately two- and fourfold greater than those estimated to be present in the pituitary. $T_{3}$ production was linear for up to 40 min (data not shown) and the 5'D-II activity carried out at

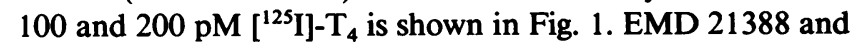
salicylate administration significantly decreased pituitary 5 DII activity at both substrate concentrations, and greater enzyme activity was present in all groups using $200 \mathrm{pM} \mathrm{T}_{4}$. This suggests that the similar levels of pituitary $T_{3}$ content seen in all groups in the first set of experiments were due to decreased enzyme activity, and not to a saturation of enzyme capacity.

Determination of free EMD 21388 activity in serum. When EMD 21388 was added to serum in increasing concentrations and then subject to equilibrium dialysis in duplicate, the percentage of $\left[{ }^{125} \mathrm{I}\right]-\mathrm{T}_{4}$ bound to TTR in normal serum mixed with dialysate is shown in Fig. 2 . In rats given 2 or $4 \mu \mathrm{mol}$ EMD $21388 / 100 \mathrm{~g}$ body wt intravenously, sacrificed $3 \mathrm{~min}$ later, there was no evidence of "free" EMD 21388 activity. $(57.5 \pm 1.6 \%$ in rats treated with $4 \mu \mathrm{mol}$ EMD $21388 / 100 \mathrm{~g}$ body wt; $58.0 \pm 1.1 \%$ at $2 \mu \mathrm{mol} / 100 \mathrm{~g}$, vs. $55.7 \pm 1.5 \%$ in controls; 4 rats per group, $P=\mathrm{NS}$ ).

Effect of salicylate added in vitro on pituitary $5^{\prime} D-I I$. To determine whether sodium salicylate was a direct inhibitor of 5'D-II, we assayed aliquots of normal pituitary homogenate for $5^{\prime} \mathrm{D}-\mathrm{II}$ activity in the presence of 0,2 , and $10 \mathrm{mM}$ sodium salicylate. The activities in triplicate samples were 47.0, 65.6, and $57.1 \mathrm{fmol}{ }^{125} \mathrm{I}$ released $\cdot \mathrm{mg}$ protein ${ }^{-1} \cdot \mathrm{h}^{-1}$, respectively (NS). Because the serum salicylate concentration in animals treated with $30 \mathrm{mg}$ salicylate/100 g body wt was $34.2 \mathrm{mg} /$ $\mathrm{dl} \pm 1.0(2.1 \mathrm{mM})$, it is clear that this administered dose of salicylate does not directly inhibit enzyme activity.

Effects of EMD 21388 and salicylate on serum TSH, total $T_{4}$, free $T_{4}$, and total $T_{3}$ concentrations. Table II illustrates the serum TSH and thyroid hormone levels in the three groups. The decrease in TSH at $1 \mathrm{~h}$ in the EMD 21388-treated group, although not statistically significant, was similar to that previously reported (18). The serum TSH concentration was also slightly lower in the salicylate-treated group. In both treatment groups there was a significant decrease in the serum total $\mathrm{T}_{4}$ concentration compared to the control group. There was a significant increase in the percent free $T_{4}$ in the EMD 21388-

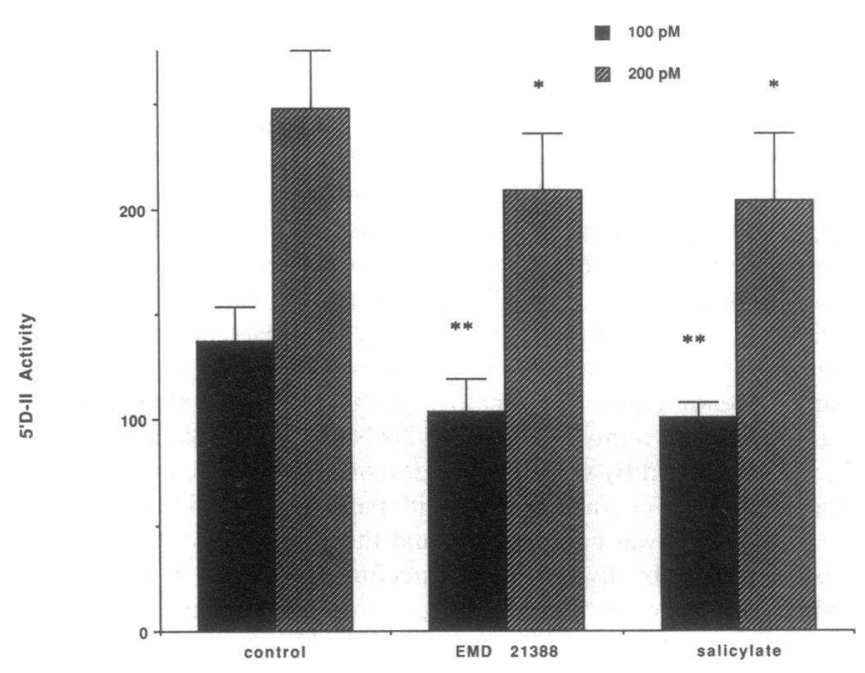

Figure 1. The effects of EMD 21388 and sodium salicylate administration on pituitary 5'D-II activity using $100 \mathrm{pM}$ and $200 \mathrm{pM}\left[{ }^{125} \mathrm{I}\right]-\mathrm{T}_{4}$ as substrates. Rats were treated with either $40 \mathrm{mM} \mathrm{NaOH}$ vehicle, $2 \mu$ mol EMD $21388 / 100 \mathrm{~g}$ body $\mathrm{wt}$, or $30 \mathrm{mg}$ sodium salicylate/100 $\mathrm{g}$ body wt and sacrificed $1 \mathrm{~h}$ later. Pituitaries were homogenized, and aliquots used to determine the $\mathrm{fmol}{ }^{125} \mathrm{I}$ released $\cdot \mathrm{mg}$ protein ${ }^{-1} \cdot \mathrm{h}^{-1}$ at each substrate concentration, after 10,20, and $40 \mathrm{~min}$ of incubation. Activities were calculated by least squares regression analysis for each animal, and the means in each treatment group are shown above. Data are reported as the mean $\pm \mathrm{SE}$ of three separate experiments, with four to eight rats per group per experiment. Error bars indicate standard error. ${ }^{*} P<0.05$ vs. control (analysis of covariance). ${ }^{* *} P<0.05$ vs. control (analysis of covariance). 


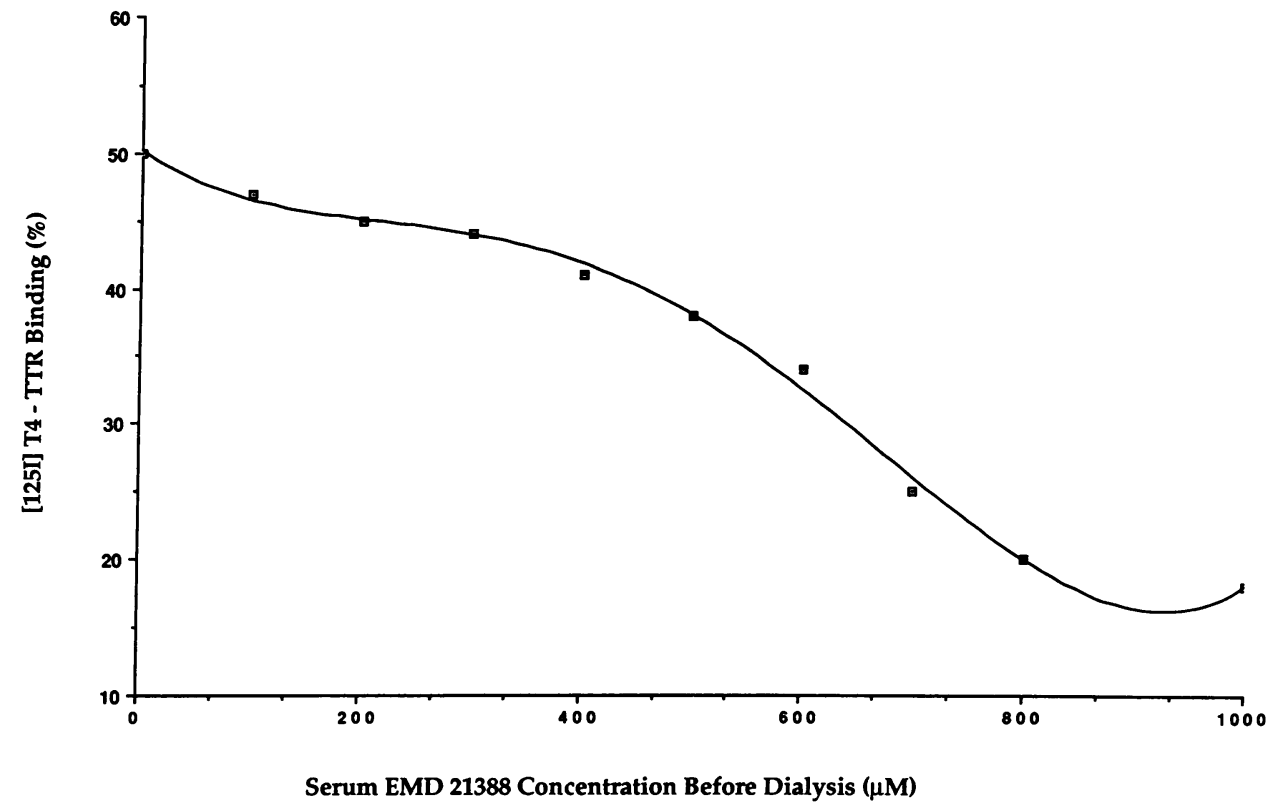

Figure 2. Estimation of serum free EMD 21388 activity. $0-1,000 \mu \mathrm{M}$ EMD 21388 was added to normal rat serum in duplicate, and $1 \mathrm{ml}$ of each was subject to equilibrium dialysis overnight. Each dialysate was added to normal rat serum containing $[125 \mathrm{I}]-\mathrm{T}_{4}$, and the mixture was subject to SDS-PAGE. The radiolabeled band corresponding to TTR was counted and expressed as a percentage of total radioactivity for that lane. treated group due to the inhibition of $\mathrm{T}_{4}$ binding by TTR, and thus, a less pronounced but still highly significant increase in the serum free $T_{4}$ concentration. Salicylate administration has been reported to increase the percent free $\mathrm{T}_{4}$ measured by equilibrium dialysis (24), and the percent free $T_{4}$ was significantly higher using this technique (salicylate-treated, $0.051 \pm 0.003 \%$, vs. control, $0.032 \pm 0.002 \%, P<0.05$ ). However, we established in a separate experiment, that $\sim 70 \%$ of the serum salicylate is present in the dialysate at equilibrium, and, therefore, equilibrium dialysis cannot accurately reflect the percent free $T_{4}$ present in vivo. Thus, the free $T_{4}$ concentration cannot be calculated. It is likely, however, that the serum free $T_{4}$ concentration in these rats is increased because Larsen has reported that salicylate, when added to human serum at a concentration of 30 $\mathrm{mg} / \mathrm{dl}$, doubles the free $\mathrm{T}_{4}$ concentration as measured by an ultrafiltration technique (25).

Serum TSH concentrations 1 and $2 h$ after administration of EMD 21388. To demonstrate that the decrease in serum TSH becomes more pronounced over time after EMD 21388 administration, rats were treated with EMD 21388 and serum

Table II. Effects of EMD 21388 and Sodium Salicylate on Serum TSH, $T_{4}$, Percent Free $T_{4}$, and $T_{3} 1 \mathrm{~h}$ after Administration

\begin{tabular}{lccc}
\hline & Control & EMD 21388 & Salicylate \\
\hline $\mathrm{TSH}(\mu U / m l)$ & $63.7 \pm 6.8$ & $55.8 \pm 4.6$ & $49.4 \pm 3.3$ \\
$\mathrm{~T}_{4}(\mu g / d l)$ & $5.68 \pm 0.02$ & $3.00 \pm 0.16^{*}$ & $2.93 \pm 0.22^{*}$ \\
$\% \mathrm{Free}_{4}$ & $0.028 \pm 0.001$ & $0.115 \pm 0.005^{*}$ & - \\
Free $\mathrm{T}_{4}(n g / d l)$ & $1.57 \pm 0.09$ & $3.42 \pm 0.23^{*}$ & - \\
$\mathrm{T}_{3}(n g / d l)$ & $81.37 \pm 4.31$ & $65.75 \pm 4.18^{*}$ & $55.38 \pm 3.67^{*}$
\end{tabular}

Serum values were measured from trunk blood obtained $1 \mathrm{~h}$ after treatment with either $40 \mathrm{mM} \mathrm{NaOH}$ vehicle, $2 \mu \mathrm{mol}$ EMD $21388 / 100$ $\mathrm{g}$ body wt, or $30 \mathrm{mg}$ sodium salicylate $/ 100 \mathrm{~g}$ body wt. Data are reported as the mean $\pm \mathrm{SE}$ of three separate experiments, with four to eight rats per group per experiment. ${ }^{*} P<0.05$ vs. controls by ANOVA and SNK.
TSH concentrations measured 1 and $2 \mathrm{~h}$ later. The results are shown in Fig. 3 and demonstrate a significantly lower serum TSH concentration in the rats treated with EMD 21388 compared with control values at $2 \mathrm{~h}$. These results are similar to those previously reported (18).

\section{Discussion}

These data demonstrate that an acute elevation in serum free $T_{4}$, due to inhibition of $T_{4}$ binding to TTR by EMD 21388, rapidly increases the pituitary and liver content of $T_{4}$. In the pituitary, this increased amount of $\mathrm{T}_{4}$ did not result in a greater $T_{3}$ content, because the enzyme catalyzing the conversion of $T_{4}$ to $\mathrm{T}_{3}, 5 \mathrm{D}$-II, was decreased. The data further indicate that this decrease in enzyme activity is directly related to the increased concentration of substrate $T_{4}$, because salicylate administra-

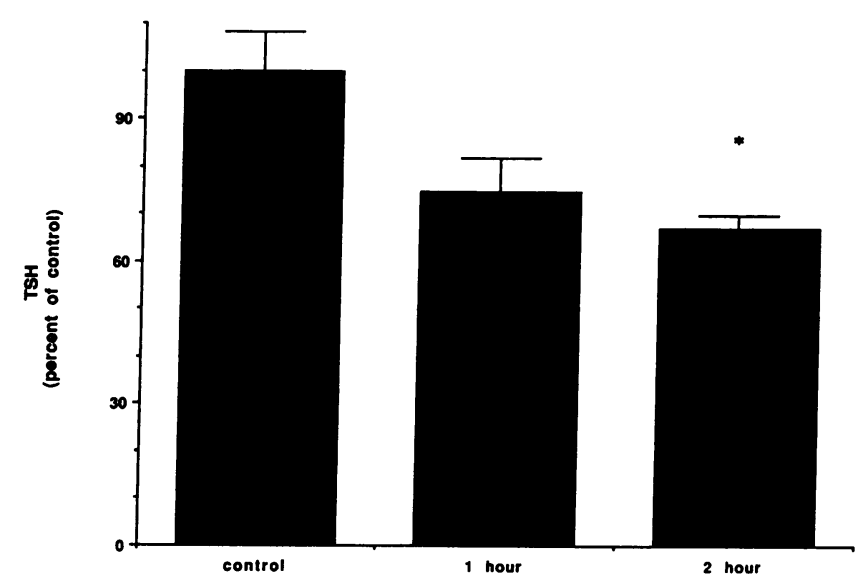

Figure 3. Serum TSH concentrations 1 and $2 \mathrm{~h}$ after EMD 21388 administration. Rats were treated with either $40 \mathrm{mM} \mathrm{NaOH}$ vehicle, or $2 \mu \mathrm{mol}$ EMD $21388 / 100 \mathrm{~g}$ body wt. There were five rats per group. Error bars indicate standard error. ${ }^{*} P<0.05$ vs. controls by ANOVA and SNK. 
tion produced a similar decrease in 5'D-II activity in vivo, but had no effect on 5'D-II activity when added in vitro. Although EMD 21388 added in vitro has been reported to competitively inhibit 5'D-II, this effect occurs only in concentrations $>1 \mu \mathrm{M}$ (26). It is highly unlikely that an administered intraperitoneal dose of $2 \mu \mathrm{mol} / 100 \mathrm{~g}$ would provide an intrapituitary concentration of $1 \mu \mathrm{M}$. Assuming that the entire injected dose is absorbed and retained in the circulation, in a $250-\mathrm{g}$ rat the maximum EMD 21388 serum concentration would be $500 \mu \mathrm{M}$ (5 $\mu \mathrm{mol} / 10 \mathrm{ml}$ serum). We have observed that the apparent "free" EMD 21388 at this serum concentration causes $\sim 24 \%$ displacement of [125I]-T from TTR. Assuming that TTR is the only serum protein that binds EMD 21388, and assuming a 1:1 stoichiometry, the concentration of free EMD 21388 would be 0.24 [TTR], or 0.24 [5.5 $\mu \mathrm{M}$ ] (27), or $1.3 \mu \mathrm{M}$. The total amount of free EMD 21388 in the $10 \mathrm{ml}$ of rat serum would therefore be $13 \mathrm{nmol}$. If that free EMD 21388 is equally distributed throughout the body, the pituitary concentration would be 13 $\mathrm{nmol} / 250 \mathrm{ml}$, or $52 \mathrm{nM}$. The effect of EMD 21388 on the activity of 5 'D-II in this system is, therefore, likely to be indirect, and caused by its ability to increase the pituitary content of $\mathrm{T}_{4}$. While in earlier work (18) this effect on pituitary 5'D-II activity was not observed, subsequent in vivo experiments have demonstrated that the potency of EMD 21388 to inhibit $T_{4}$ binding to TTR is increased (17) perhaps due to the use of a more alkaline vehicle in the more recent experiments (17). This might result in a greater amount of free $T_{4}$ available to the pituitary to decrease 5 'D-II activity.

The ability of $T_{4}$ to regulate intrapituitary $T_{3}$ production has been verified by numerous investigators. Incubation of pituitary fragments (11) or $\mathrm{GH}_{4} \mathrm{C}_{1}$ cells (12) with increasing concentrations of $T_{4}$ resulted in a decrease in deiodination of $T_{4}$ and $T_{3}$ production. Others have shown that rats treated with $T_{4}$ exhibit decreased pituitary deiodinase activity (13-15). Leonard et al. have reported that this effect is not inhibited by cycloheximide and is, therefore, not dependent on protein synthesis (16). Finally, Lum and co-workers have suggested that 5 -deiodinase activity is autoregulated in man, being reduced when serum $\mathrm{T}_{4}$ concentration is elevated, and increased in the presence of a lower $T_{4}$ value (28). The present study demonstrates that in euthyroid rats, the basal activity of $5 \mathrm{D}$-II can be decreased by $\sim 25 \%$ in $1 \mathrm{~h}$ by an increase in pituitary $\mathrm{T}_{4}$ content without the administration of pharmacologic doses of $L-T_{4}$.

We have also demonstrated that, in the absence of an increase in intrapituitary $T_{3}$ levels, TSH begins to decrease at $1 \mathrm{~h}$ and decreases even further $2 \mathrm{~h}$ after EMD 21388 administration. Because previous data indicate that EMD 21388 has a low affinity for the $T_{3}$ nuclear receptor (29), and the intracellular $T_{3}$ that we measured is in dynamic equilibrium with nuclear $T_{3}$, there is no reason to expect a difference in $T_{3}$ nuclear receptor occupancy between EMD 21388-treated and control rats. Therefore, basal TSH secretion may decrease independently of the $T_{3}$ nuclear content.

The importance of $\mathrm{T}_{3}$ in inhibiting TSH release is clear and has been reported to be more important than $T_{4}$. Hypothyroid rats treated with iopanoic acid (which blocks both intrapituitary and systemic $T_{4}$ to $T_{3}$ conversion) have a lower pituitary nuclear $T_{3}$ content than control rats, and TSH secretion is not decreased in response to an intravenous bolus of $T_{4}(5)$. Additionally, $\mathrm{T}_{4}$ does not inhibit the TRH-induced increase in TSH secretion after pretreatment with iopanoic acid (7). Further- more, Emerson et al. have recently reported that serum $T_{3}$ concentrations are more positively correlated with TSH secretion than serum $T_{4}$ concentrations under physiological conditions (8). Therefore, it is possible that a critical percentage of nuclear $\mathrm{T}_{3}$ receptors must be occupied to suppress TSH secretion and maintain a basal secretory rate in the euthyroid rat. However, we have now demonstrated that elevations in pituitary $\mathrm{T}_{4}$ content may decrease basal TSH secretion without an associated increase in pituitary $\mathrm{T} 3$ content.

It is important to note, however, that thyrotrophs constitute only $\sim 10 \%$ of the euthyroid pituitary (30), and we may not be observing an accurate reflection of 5 D-II activity and iodothyronine content in these cells. Studies of enriched pituitary cell pools have shown that, while under hypothyroid conditions, thyrotrophs have less 5 - $-\mathrm{D}$ activity than other anterior pituitary cell types, $T_{3}$ replacement induces a similar, lower level of activity in all cell pools (31). This may indicate that the $5^{\prime} \mathrm{D}$-II may be less substrate-regulated in the thyrotroph than in other cell types, and it is possible that proportionately more thyrotroph-derived $T_{3}$ is available to its nucleus when pituitary $\mathrm{T}_{4}$ content is elevated. Alternatively, the thyrotroph may be dependent, in a paracrine fashion, on $T_{3}$ generated by other pituitary cell types. When $T_{3}$ availability decreases within the pituitary, TSH secretion is stimulated. However, when $\mathrm{T}_{4}$ content increases, $T_{3}$ production is blunted in other cell types such as lactotrophs and somatotrophs, and these cells are protected from increased amounts of $T_{3}$ generated by unchecked local conversion. Under these conditions the total pool of $T_{3}$ available to the thyrotroph is not different from the euthyroid state, but an additional signal for suppressing TSH secretion, $\mathrm{T}_{4}$, remains intact.

In summary, we have demonstrated that an acute elevation in serum free $T_{4}$ concentration can increase pituitary (and liver) $T_{4}$ content, and can rapidly decrease the activity of pituitary $5^{\prime} \mathrm{D}$-II. Pituitary $\mathrm{T}_{3}$ content does not change and, despite this, TSH secretion decreases. These results suggest that $T_{4}$ may have an effect on TSH secretion independent of its conversion to $T_{3}$, and may explain how TSH secretion can decrease in the presence of a decrease in $5^{\prime} \mathrm{D}-\mathrm{II}$ activity.

\section{Acknowledgments}

The authors wish to express their appreciation to Mr. Sam Pino, Mr. Scott Stone, Dr. Denis Meerdink, and Ms. Michelle Thurber for their technical assistance.

This work was supported in part by grants DK 18919, DK 07302, and DK 38772 from National Institutes of Diabetes, Digestive and Kidney Diseases, National Institutes of Health, Bethesda, MD.

\section{References}

1. Morley, J. E. 1981. Neuroendocrine control of thyrotropin secretion. Endocr. Rev. 2:396-436.

2. Larsen, P. R., and R. D. Frumess. 1977. Comparison of the biological effects of thyroxine and triiodothyronine in the rat. Endocrinology. 100:980-988.

3. Silva, J. E., and P. R. Larsen. 1977. Pituitary nuclear 3,5,3'-triiodothyronine and thyrotropin secretion: an explanation for the effect of thyroxine. Science (Wash. DC). 198:617-620.

4. Silva, J. E., and P. R. Larsen. 1978. Contributions of plasma triiodothyronine and local thyroxine monodeiodination to triiodothyronine to nuclear triiodothyronine receptor saturation in pituitary, liver, and kidney of hypothyroid rats. Further evidence relating saturation of pituitary nuclear triiodothyronine receptors and the acute inhibition of thyroid-stimulating hormone release. $J$. Clin. Invest. 63:1247-1259. 
5. Larsen, P. R., T. E. Dick, B. P. Markovitz, M. M. Kaplan, and T. G. Gard. 1979. Inhibition of intrapituitary thyroxine to 3,5,3'-triiodothyronine conversion prevents the acute suppression of thyrotropin release by thyroxine in hypothyroid rats. J. Clin. Invest. 64:117-128.

6. Obregon, M. J., A. Pasqual, J. Mallol, G. Morreale de Escobar, and F. Escobar del Rey. 1980. Evidence against a major role of L-thyroxine at the pituitary level: studies in rats treated with iopanoic acid (Telepaque). Endocrinology. 106:1827-1836.

7. Maruta, S., and M. A. Greer. 1988. Evidence that thyroxine inhibits either basal or TRH-induced TSH secretion only after conversion to triiodothyronine. Proc. Soc. Exp. Biol. Med. 187:391-397.

8. Emerson, C. H., R. Lew, L. E. Braverman, and W. J. DeVito. 1989. Serum thyrotropin concentrations are more highly correlated with serum triiodothyronine concentrations than with serum thyroxine concentrations in thyroid-hormone-infused thyroidectomized rats. Endocrinology. 124:2415-2418.

9. Silva, J. E., T. E. Dick, and P. R. Larsen. 1978. The contribution of local tissue thyroxine monodeiodination to the nuclear 3,5,3'-triodothyronine in pituitary, liver, and kidney of euthyroid rats. Endocrinology. 103:1196-1207.

10. Visser, T. J., M. M. Kaplan, J. L. Leonard, and P. R. Larsen. 1983. Evidence for two pathways of iodothyronine 5 -deiodination in rat pituitary that differ in kinetics, propylthiouracil sensitivity, and response to hypothyroidism. $J$. Clin. Invest. 71:992-1002.

11. Cheron, R. G., M. M. Kaplan, and P. R. Larsen. 1979. Physiological and pharmacological influences on thyroxine to 3,5,3'-triiodothyronine conversion and nuclear 3,5,3'-triiodothyronine binding in rat anterior pituitary. J. Clin. Invest. 64:1402-1414.

12. Koenig, R. L. 1986. Regulation of thyroxine 5'-deiodinase by thyroid hormones and activators of protein kinase $\mathrm{C}$ in $\mathrm{GH}_{4} \mathrm{C}_{1}$ cells. Endocrinology. 118:1491-1497.

13. Silva, J. E., and J. L. Leonard. 1985. Regulation of rat cerebrocortical and adenohypophyseal type II 5 -deiodinase by thyroxine, triiodothyronine, and reverse triiodothyronine. Endocrinology. 116:1627-1635.

14. Maeda, M., and S. H. Ingbar. 1982. Effect of alteration in thyroid status on the metabolism of thyroxine and triiodothyronine by rat pituitary gland in vitro. J. Clin. Invest. 69:799-808.

15. Goswami, A., and I. N. Rosenberg. 1990. Regulation of iodothyronine 5'-deiodinases: effects of thiol blockers and altered substrate levels in vivo and in vitro. Endocrinology. 126:2597-2606.

16. Leonard, J. L., J. E. Silva, M. M. Kaplan, S. A. Mellen, T. J. Visser, and P. R. Larsen. 1984. Acute posttranscriptional regulation of cerebrocortical and pituitary iodothyronine $5^{\prime}$-deiodinases by thyroid hormone. Endocrinology. 114:998-1002.

17. Lueprasitsakul, W., S. Alex, S. L. Fang, S. Pino, K. Irmscher, J. Kohrle, and L. E. Braverman. 1990. Flavonoid administration immediately displaces thyroxine $\left(T_{4}\right)$ from serum transthyretin, increases serum free $T_{4}$, and decreases serum thyrotropin in the rat. Endocrinology. 126:2890-2895.
18. Kohrle, J., S. L. Fang, Y. Yang, K. Irmscher, R. D. Hesch, S. Pino, S. Alex, and L. E. Braverman. 1989. Rapid effects of the flavonoid EMD 21388 on serum thyroid hormone binding and thyrotropin regulation in the rat. Endocrinology. 125:532-537.

19. Weeke, J., and H. Orskov. 1973. Synthesis of monolabelled 3,5,3'triiodothyronine and thyroxine of maximum specific activity for radioimmunoassay. Scand. J. Clin. Invest. 32:357-363.

20. Bellabarba, D., R. E. Peterson, and K. Sterling. 1968. An improved method for chromatography of iodothyronines. J. Clin. Endocrinol. Metab. 28:305-307.

21. Young, R. A., E. Danforth, Jr., A. Vagenakis, P. P. Krupp, R. Frink, and E. A. H. Sims. 1979. Seasonal variation and the influence of body temperature on plasma concentrations and binding of thyroxine and triiodothyronine in the woodchuck. Endocrinology. 104:996-1001.

22. Blanke, R. V. 1976. Analysis of drugs and toxic substances. In Fundamentals of Clinical Chemistry. N. Tietz, editor. W. B. Saunders \& Co., Philadelphia. 1100-1162.

23. Davis, P. J., S. W. Spaulding, and R. I. Gregerman. 1970. The three thyroxine-binding capacities and effects of binding inhibitors. Endocrinology. 87:978-986.

24. Good, B. F., B. S. Hetzel, and B. M. Hogg. 1965. Studies of the control of thyroid function in rats: effects of salicylate and related drugs. Endocrinology. 77:674-682.

25. Larsen, P. R. 1972. Salicylate-induced increases in free triiodothyronine in human serum. J. Clin. Invest. 51:1125-1134.

26. Farwell, A. P., and J. L. Leonard. 1989. Identification of a 27-kDa protein with the properties of type II iodothyronine 5'-deiodinase in dibutyryl cyclic AMP-stimulated glial cells. J. Biol. Chem. 264:20561-20567.

27. Navab, M., J. E. Smith, and D. S. Goodman. 1977. Rat plasma prealbumin. Metabolic studies on effects of vitamin A status and on tissue distribution. $J$. Biol. Chem. 252:5107-5114.

28. Lum, S. M. C., J. T. Nicoloff, C. A. Spencer, and E. M. Kaptein. 1984. Peripheral tissue mechanism for maintenance of serum triiodothyronine values in a thyroxine-deficient state in man. J. Clin. Invest. 73:570-575.

29. Kohrle, J., M. Spanka, K. Irmscher, and R. D. Hesch. 1988. Flavonoid effects on transport, metabolism and action of thyroid hormones. In Plant Flavonoids in Biology and Medicine. II. Biochemical, Cellular, and Medicinal Properties. V. Cody, E. Middleton, J. B. Harborne, and A. Beretz, editors. Alan R. Liss, Inc., New York. 323-345.

30. Surks, M. I., and C. R. DeFesi. 1977. Determination of the cell number of each type in the anterior pituitary of euthyroid and hypothyroid rats. Endocrinology. 101:946-958.

31. Koenig, R. J., J. L. Leonard, D. Senator, N. Rappaport, A. Y. Watson, and P. R. Larsen. 1984. Regulation of thyroxine 5'deiodinase activity by 3,5,3'triiodothyronine in cultured rat anterior pituitary cells. Endocrinology. 114:324329. 